\title{
Mechanism of injection pain with long and long- medium chain triglyceride emulsive propofol
}

\author{
[Le mécanisme de la douleur à l'injection d'une émulsion de propofol et de chaînes
}

longues et mi-longues de triglycérides]

Hiroshi Ohmizo DDS, Shinju Obara MD, Hiroshi Iwama MD

Purpose: $t$ has been suggested that long-medium chain triglyceride (LCT/MCT) emulsive propofol causes less injection pain than long chain triglyceride (LCT) emulsive propofol because of the decreased propofol concentration in the aqueous phase. Alternatively, LCT propofol generates bradykinin causing the injection pain and activates complement, but these effects when using LCT/MCT propofol have not been examined. To identify the mechanism for reduced pain with LCT/MCT propofol, injection pain, bradykinin generation and complement activation with use of both propofol products were compared.

Methods: Two hundred adult patients randomly allocated to two groups were given $1.5 \mathrm{mg} \cdot \mathrm{kg}^{-1}$ iv of either LCT propofol or LCT/MCT propofol at a rate of $200 \mathrm{mg} \cdot \mathrm{min}^{-1}$ in a double-blind manner and were asked to grade pain scores. In another study, bradykinin and activated complement 3 (C3a) concentrations were measured using blood obtained from 13 healthy volunteers mixed with saline, LCT propofol or LCT/MCT propofol.

Results: There was a significant difference in pain scores between groups, showing a lower incidence of injection pain in the LCT/MCT propofol group. The bradykinin concentrations in blood mixed with LCT and LCT/MCT propofol were significantly higher than in blood mixed with saline. The C3a concentrations showed similar results.

Conclusions: LCT/MCT propofol causes less pain on injection compared with LCT propofol. Bradykinin generation and complement activation are similar with both LCT and LCT/MCT propofol. Thus, the reason for less pain on injection with LCT/MCT propofol may be attributed to a decreased concentration of propofol in the aqueous phase.
Objectif: On a pensé qu'une émulsion de propofol avec une chaîne mi-longue de triglycéride (CLT/CMT) cause moins de douleur à l'injection qu'une émulsion à chaîne longue (CLT) parce que la concentration de propofol diminue pendant la phase aqueuse. Aussi, le propofol avec CLT génère de la bradykinine, causant de la douleur à l'injection, et active le complément, mais ces effets n'ont pas été étudiés avec le propofol CLT/CMT. Pour définir le mécanisme qui réduit la douleur avec le propofol CLT/CMT, nous avons comparé la douleur à l'injection, la génération de bradykinine et l'activation du complément avec l'usage des deux produits de propofol.

Méthode : Deux cents patients adultes ont été répartis au hasard en deux groupes et ont reçu $1,5 \mathrm{mg} \cdot \mathrm{kg}^{-1}$ iv de propofol CLT ou CLT/CMT à $200 \mathrm{mg} \cdot \mathrm{min}^{-1}$ en double aveugle. On a demandé aux patients d'évaluer leur douleur. Dans une autre étude, les concentrations de bradykinine et de complément 3 activé (C3a) ont été mesurées dans des échantillons sanguins, obtenus de 13 volontaires sains, mêlés à une solution salée, à du propofol CLT ou CLT/CMT.

Résultats : On a noté une différence significative de scores de douleur, montrant une plus faible incidence avec le propofol CLT/CMT. Les concentrations de bradykinine dans le sang mêlé au propofol CLT et CLT/CMT ont été significativement plus élevées que dans le sang mêlé à la solution saline. Les concentrations de C3a ont montré des résultats similaires.

Conclusion : Le propofol CLT/CMT cause moins de douleur à l'injection que le propofol CLT. La génération de bradykinine et l'activation de complément sont similaires avec le propofol CLT et CLT/CMT. Par conséquent, la diminution de la douleur avec le propofol CLT/CMT peut être attribuée à la plus faible concentration de propofol pendant la phase aqueuse.

From the Department of Anesthesiology, Central Aizu General Hospital, Aizuwakamatsu, Japan.

Address correspondence to: Dr. Hiroshi Iwama, Department of Anesthesiology, Central Aizu General Hospital, 1-1 Tsuruga-machi,

Aizuwakamatsu City 965-0011, Japan. Fax: +81-242-24-1529; E-mail: iwama@onchikai.jp

Accepted for publication January 28, 2005.

Revision accepted March 7, 2005. 
$\mathrm{P}$ ROPOFOL is widely used to induce and maintain anesthesia as well as for sedation of intensive care patients. Since propofol is water insoluble and causes severe pain on injection, it has been formulated as a $1 \%$ solution in a fat emulsion containing $10 \%$ soybean oil consisting of long chain triglycerides (LCT). However, about half of patients still experience moderate to severe pain on injection. ${ }^{1-3}$ Thus, several methods have been devised to prevent this pain, for example injection into a larger vein, use of various drugs (aspirin, fentanyl, alfentanil, metoclopramide, nitroglycerin, prilocaine, pethidine $),{ }^{4-9}$ and co-administration with either lidocaine or nafamostat mesilate (a kallikrein inhibitor), ${ }^{2,3,10,11}$ of which the most effective and common are use of a larger vein and mixing with lidocaine. Regarding one of the mechanisms of injection pain, our recent studies demonstrated generation of the bradykinin caused by propofol and its inhibitory effect of lidocaine and nafamostat mesilate, so that these two drugs are considered to decrease the pain by reducing the plasma bradykinin levels. ${ }^{2,3}$ Bradykinin is produced by contact between the lipid solvent for propofol and the plasma kallikrein-kinin system, and results in modification of the injected vein, such that the propofol in the aqueous phase has easy access to the free nerve endings of the vessel, causing aggravation of the pain. ${ }^{3}$ In addition, it has recently been reported that use of $10 \%$ long and medium chain triglycerides (LCT/MCT) mixed at a $1: 1$ ratio in the carrier emulsion, as an alternative to LCT, reduces pain without any changes in the pharmacokinetics and pharmacodynamics. It was suggested that this can be attributed to a decreased concentration of the aqueous phase propofol. ${ }^{12-15}$

According to the above reports, reduction of bradykinin generation or propofol concentration in the aqueous phase may be the main reasons for reduced pain on injection with propofol emulsified in LCT/MCT. Although a decrease in the aqueous phase propofol in this emulsion has been demonstrated, ${ }^{16}$ the effect on bradykinin generation has not been examined. Apart from the pain, it has been demonstrated that complement is activated by LCT. ${ }^{17}$ Although the clinical implication of this complement activation is unclear, it may be important, because it has been associated with pulmonary edema. ${ }^{18-20}$ Furthermore, the effect of LCT/MCT on complement activation has not been examined. In this report, injection pain, bradykinin generation and complement activation with use of LCT emulsive propofol and LCT/MCT emulsive propofol were compared to identify the mechanism for reduced pain when using LCT/MCT propofol.

\section{Materials and methods}

The following studies were approved by our Institutional Ethical Committee, and all patients and volunteers associated with the studies provided written informed consent. One percent propofol emulsified in 10\% LCT (Diprivan, Astra Zeneca, Osaka, Japan) and $1 \%$ propofol emulsified in $10 \%$ LCT $/ M C T$ at a 1:1 ratio (Propofol, Maruishi, Osaka, Japan) were used and regarded as LCT and LCT/MCT propofol, respectively.

\section{Comparison of injection pain}

Two hundred elective and adult operative patients classified as ASA I or II were allocated randomly to the LCT or LCT/MCT propofol groups. The patients were not premedicated. After entering the operating room, each patient received a $20-\mathrm{G}$ iv catheter in the forearm. Subsequently, $1.5 \mathrm{mg} \cdot \mathrm{kg}^{-1}$ of either LCT propofol or LCT/MCT propofol were injected at a rate of $200 \mathrm{mg} \cdot \mathrm{min}^{-1}$ in a double-blind manner. During induction, patients were repeatedly asked to report and grade any discomfort or pain of hightest score as: none $=0$; discomfort $=1 ;$ mild pain $=2 ;$ moderate pain $=3$; severe pain $=4$.

\section{Bradykinin generation and complement activation}

Thirteen adult healthy volunteers with no medical history and not taking any medication were enrolled into this part of the study. Three plastic tubes, one of each containing $2 \mathrm{~mL}$ of saline, LCT propofol or LCT/MCT propofol, were prepared at room temperature. Venous blood $(12 \mathrm{~mL})$ was collected from the cubital vein of volunteers by a plastic syringe whilst using a proximal venous tourniquet, and $4 \mathrm{~mL}$ of blood was injected into each of the prepared tubes. Each sample was shaken mildly for $20 \mathrm{sec}$, and then $4 \mathrm{~mL}$ was mixed immediately with edetic acid, aprotinin and trypsin inhibitor for bradykinin measurement and $2 \mathrm{~mL}$ was mixed with edetic acid and nafamostat mesilate for activated complement 3 (C3a) measurement. All tubes were then centrifuged at $4^{\circ} \mathrm{C}$. The supernatant for bradykinin measurement was assayed using a radioimmunoassay kit (SRL Co., Tokyo, Japan), ${ }^{3,21}$ and that for C3a measurement was assayed by radioimmunoassay (Human Complement C3a des Arg [125I] Assay System, Amersham International, Bucks, UK). ${ }^{17,22}$ The sensitivity level and coefficient of variation for the intraassay and inter-assay were $2.0 \mathrm{pg} \cdot \mathrm{mL}^{-1}, 7.7-21.7 \%$, $9.4-14.9 \%$ in the bradykinin, and $40 \mathrm{ng} \cdot \mathrm{mL}^{-1}$, $5.0-8.7 \%, 16.5-20.5 \%$ in the C3a. 
TABLE Comparison of injection pain with use of long chain triglyceride (LCT) emulsive propofol or long-medium chain triclyceride (LCT/MCT) emulsive propofol

\begin{tabular}{llllll}
\hline & & \multicolumn{2}{c}{ Pain score } & & \\
& 0 & 1 & 2 & 3 & 4 \\
\hline LCT $(n=102)$ & $39(38.2 \%)$ & $16(15.7 \%)$ & $21(20.6 \%)$ & $18(17.7 \%)$ & $8(7.8 \%)-7$ * \\
LCT $/$ MCT $(n=98)$ & $62(63.3 \%)$ & $13(13.3 \%)$ & $15(15.3 \%)$ & $7(7.1 \%)$ & $1(1.0 \%)$ \\
\hline
\end{tabular}

Number of patients (\%). Pain scores are $0=$ none; $1=$ discomfort; $2=$ mild pain; $3=$ moderate pain; and $4=$ severe pain. ${ }^{*} P<0.01$ between the groups.

\section{Statistics}

Differences between groups with respect to age, weight, height, male/female ratio, ASA I-II distribution, and pain scores were analyzed by the unpaired $t$ test or the Mann-Whitney $U$ test. Comparison of bradykinin or C3a concentration between the saline, LCT propofol and LCT/MCT propofol groups was analyzed by the Kruskal-Wallis test with Bonferroni correction. Results are expressed as mean \pm SD (range) or number of patients. $P<0.05$ was considered significant.

\section{Results}

Comparison of injection pain

The LCT and LCT/MCT propofol groups contained 102 patients and 98 patients, respectively. They were similar in age $(53 \pm 16(18-83)$ vs $49 \pm 16(18-83)$ yr), weight $(57 \pm 11(32-91)$ vs $58 \pm 10(40-80) \mathrm{kg})$, height $(157 \pm 9(141-185)$ vs $160 \pm 9(129-183)$ $\mathrm{cm})$, male/female ratio $(35 / 67$ vs $45 / 53)$, and ASA I-II distribution (4l/61 vs 48/50). There was a significant difference in the pain scores between groups, showing a lower incidence of injection pain in the LCT/MCT propofol group (Table).

\section{Bradykinin generation and complement activation}

The age, weight and height of the volunteers were 32 $\pm 7(2 \mathrm{l}-48) \mathrm{yr}, 60 \pm 11(43-80) \mathrm{kg}$ and $162 \pm 9$ $(147-176) \mathrm{cm}$, respectively. Seven volunteers were male and six were female. The result of bradykinin measurement showed that the concentration in the LCT and LCT/MCT propofol samples was significantly higher than in the saline sample. Also, the result of C3a measurement showed that the concentration in the LCT and LCT/MCT propofol samples was significantly higher than in the saline sample (Figure).

\section{Discussion}

The reason why propofol causes pain on injection was considered in our previous study using nafamostat mesilate, a kallikrein inhibitor, as follows: the lipid sol- vent (LCT) for propofol activates the plasma kallikrein-kinin system during injection, generating bradykinin that causes hyperpermeability of the vessel and thus dilates the injected local vein. As a result, there is increased contact between the aqueous phase propofol and the free nerve endings of the vessel, resulting in aggravation of propofol-induced pain. ${ }^{3}$ When bradykinin generation is reduced by the pharmacological effect of nafamostat mesilate, the propofol-induced pain is decreased. Alternatively, the decrease in pain when using LCT/MCT propofol is considered to be attributed to the lipid solvent that decreases the propofol concentration in the aqueous phase. ${ }^{12-15}$ Association between the aqueous phase propofol concentration and injection pain has also been reported in some studies. ${ }^{23,24}$ Thus, it is possible that a reduction in either bradykinin generation or the aqueous phase propofol concentration decreases the pain on injection with propofol.

The results obtained from the present study indicate that LCT/MCT propofol causes less pain on injection than LCT propofol. In the bradykinin or C3a measurement, we aspirated blood into each tested solution at a ratio of 2:1, followed by $20 \mathrm{sec}$ of shaking, a procedure which is in accordance with our previous reports. ${ }^{3,17}$ By mixing blood with propofol at this ratio, bradykinin and $\mathrm{C} 3 \mathrm{a}$ levels increase about twofold. However, because an actual mixing ratio in the clinical setting is unknown, these increases were assumed to serve as reference. Both the LCT and LCT/MCT propofol were associated with a twofold increase of bradykinin levels, compared with saline control, suggesting that both products have the same effect on bradykinin generation. Thus, the reason for decreased injection pain with use of LCT/MCT propofol is most likely attributed to its lipid solvent characteristic that reduces the aqueous phase propofol concentration. Since bradykinin generation occurs similarly with both propofol products, injection pain with use of LCT/MCT propofol may be further decreased when it is co-administrated with nafamostat 


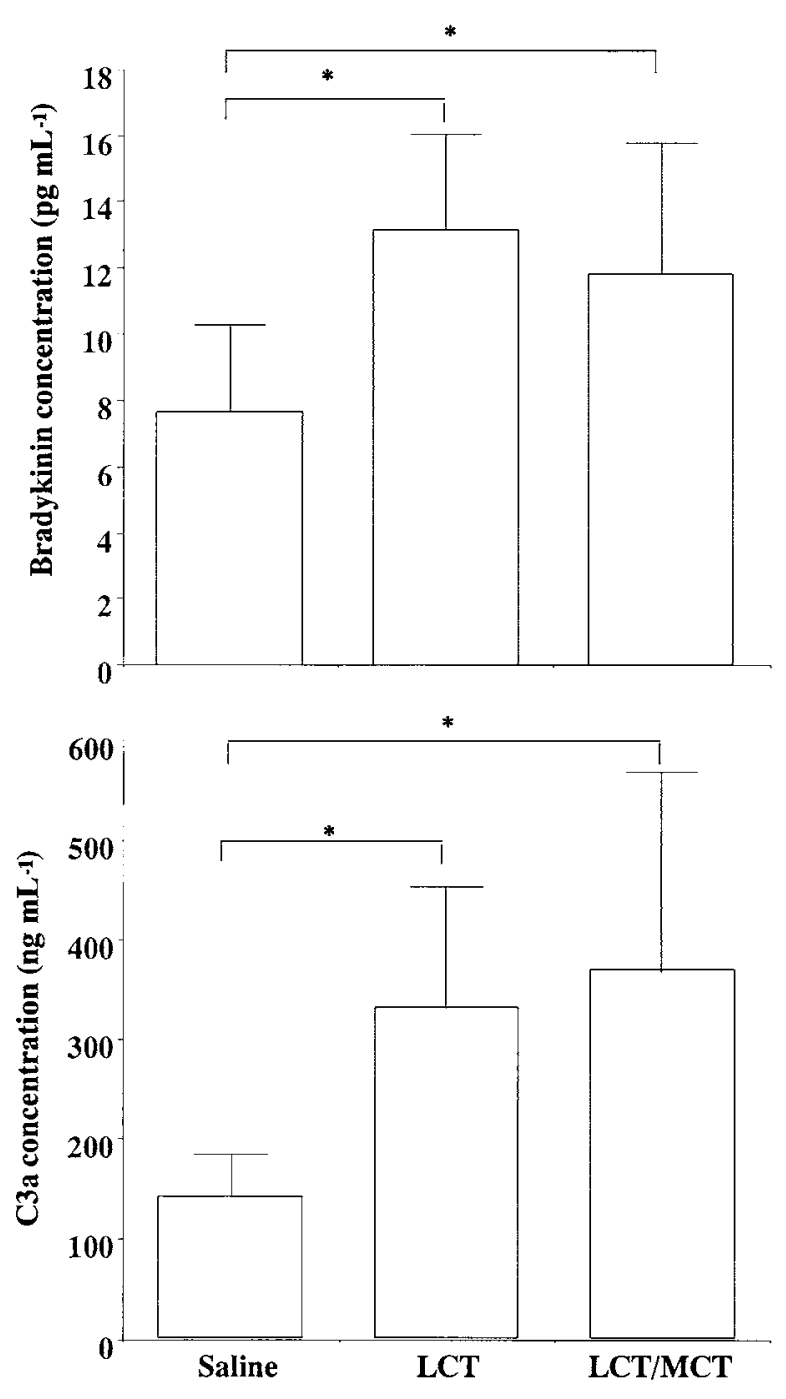

FIGURE Bradykinin and activated complement 3 (C3a) concentrations when blood is mixed with the saline, long chain triglyceride (LCT) emulsive propofol or long-medium chain triglyceride (LCT/MCT) emulsive propofol. Values are mean \pm SD. $n=13$.

${ }^{*} P<0.01$ between the groups.

mesilate or lidocaine, by reducing the bradykinin generation..$^{2,3,11}$ Further studies to explore this hypothesis may be needed.

The lipid solvent of LCT/MCT has been used widely for parenteral nutrition and is recognized as a safe caloric substrate, showing rapid lipometabolism, no adverse effect on liver function and a lower adverse effect on the immune and reticuloendothelial systems compared to LCT. ${ }^{25-28}$ The lipid solvents generate bradykinin probably because of their negative charge, ${ }^{3}$ which may explain the similar physiological properties observed with both LCT and LCT/MCT.

Regarding complement activation by propofol, it has been reported that its lipid solvent (LCT) activates the plasma complement system, by which complement 3 is activated and C3a is released. ${ }^{17}$ The present study comparing C3a concentrations with use of LCT and LCT/MCT propofol revealed that propofol in both solvents activated complement 3 similarly, suggesting that both lipid solvents have the same effect on complement activation. Although the clinical relevance of complement activation by propofol is not clear, ${ }^{17}$ the possibility of the occurrence of complications such as pulmonary edema should be considered. ${ }^{29,30}$ So far, however, no reports have shown the occurrence of pulmonary edema with use of LCT/MCT propofol.

In conclusion, LCT/MCT propofol causes less pain on injection compared with LCT propofol. Bradykinin generation and complement activation are similar with use of both the LCT and LCT/MCT propofol. Thus, the reason for less pain on injection with LCT/MCT propofol is most likely attributed to a decreased concentration of propofol in the aqueous phase.

\section{Acknowledgement}

The authors thank professor Genji Someya, Department of Dental Anesthesiology, Niigata University Graduate School of Medical and Dental Sciences, Niigata, Japan, for reviewing the manuscript.

\section{References}

1 Nathanson MH, Gajraj NM, Russel JA. Prevention of pain on injection of propofol: a comparison of lidocaine with alfentanil. Anesth Analg 1996; 82: 469-71.

2 Iwama $H$, Nakane $M$, Obmori S, et al. Nafamostat mesilate, a kallikrein inhibitor, prevents pain on injection with propofol. Br J Anaesth 1998; 81: 963-4.

3 Nakane M, Iwama $H$. A potential mechanism of propofol-induced pain on injection based on studies using nafamostat mesilate. Br J Anaesth 1999; 83: 397-404.

4 Bahar M, McAteer E, Dundee JW, Briggs LP. Aspirin in the prevention of painful intravenous injection of disoprofol (ICI 35,868) and diazepam (Valium). Anaesthesia 1982; 37: 847-8.

5 Ganta R, Fee JP. Pain on injection of propofol: comparison of lignocaine with metoclopramide. $\mathrm{Br} \mathrm{J}$ Anaesth 1992; 69: 316-7.

6 Wilkinson D, Anderson M, Gauntlett IS. Pain on injection of propofol: modification by nitroglycerin. Anesth Analg 1993; 77: 1139-42.

7 Fletcher JE, Seavell CR, Bowen DJ. Pretreatment with alfentanil reduces pain caused by propofol. Br J 
Anaesth 1994; 72: 342-4.

8 Eriksson $M$. Prilocaine reduces injection pain caused by propofol. Acta Anaesthesiol Scand 1995; 39: 210-3.

9 Lyons B, Lohan D, Flynn C, McCarroll M. Modification of pain on injection of propofol. A comparison of pethidine and lignocaine. Anaesthesia 1996; 51 : 394-5.

10 Eriksson M, Englesson S, Niklasson F, Hartvig P. Effects of lignocaine and $\mathrm{pH}$ on propofol-induced pain. $\mathrm{Br} \mathrm{J}$ Anaesth 1997; 78: 502-6.

11 Iwama $H$. A randomized, double-blind trial comparing the effect of mixing propofol with either lidocaine or nafamostat mesilate on injection pain. J Anesth 2000; 14: 164-5.

12 Doenicke AW, Roizen MF, Rau J, et al. Pharmacokinetics and pharmacodynamics of propofol in a new solvent. Anesth Analg 1997; 85: 1399-403.

13 Ran J, Roizen MF, Doenicke AW, O'Connor MF, Strohschneider $U$. Propofol in an emulsion of long- and medium-chain triglycerides: the effect of pain. Anesth Analg 2001; 93: 382-4.

14 Larsen B, Beerhalter U, Biedler A, et al. Less pain on injection by a new formulation of propofol?: a comparison with propofol LCT (German). Anaesthesist 2001; 50: $842-5$.

15 Schaub E, Kern C, Landau R. Pain on injection: a double-blind comparison of propofol with lidocaine pretreatment versus propofol formulated with long- and medium-chain triglycerides. Anesth Analg 2004; 99: 1699-702.

16 Babl J, Doenicke A, Mönch V. New formulation of propofol in an LCT/MCT emulsion. Approach to reduce pain on injection. Eur Hosp Pharm 1995; 1: 15-21.

17 Obmizo H, Iwama H, Sugita T. Complement activation by propofol and its effect during propofol anaesthesia. Anaesth Intensive Care 1999; 27: 623-7.

18 Jacob HS, Craddock PR, Hammerschmidt DE, Moldow CF. Complement-induced granulocyte aggregation. N Engl J Med 1980; 302: 789-94.

19 Solomkin JS, Cotta LA, Satoh PS, Hurst JM, Nelson RD. Complement activation and clearance in acute illness and injury: evidence for $\mathrm{C} 5 \mathrm{a}$ as a cell-directed mediator of the adult respiratory distress syndrome in man. Surgery 1985; 97: 668-78.

20 Moat NE, Shore DF, Evans TW. Organ dysfunction and cardiopulmonary bypass: the role of complement and complement regulatory proteins (Editorial). Eur J Cardiothorac Surg 1993; 7: 563-73.

21 Iwama $H$. Bradykinin-associated reactions in white cell-reduction filter. J Crit Care 2001; 16: 74-81.

22 Wagner JL, Hugli TE. Radioimmunoassay for anaphylatoxins: a sensitive method for determining comple- ment activation products in biological fluids. Anal Biochem 1984; 136: 75-88.

23 Klement W, Arndt JO. Pain on injection of propofol: effects of concentration and diluent. Br J Anaesth 1991; 67: 281-4.

24 Doenicke AW, Roizen MF, Rau J, Kellermann W, Babl $J$. Reducing pain during propofol injection: the role of the solvent. Anesth Analg 1996; 82: 472-4.

25 Dennison AR, Ball M, Hands LJ, Crowe PJ, Watkins $R M$, Kettlewell $M$. Total parental nutrition using conventional and medium chain triglycerides: effect on liver function tests, complement, and nitrogen balance. JPEN J Parenter Enteral Nutr 1988; 12: 15-9.

26 Sedman PC, Somers SS, Ramsden CW, Brennan TG, Guillou PJ. Effects of different lipid emulsions on lymphocyte function during total parenteral nutrition. Br J Surg 1991; 78: 1396-9.

27 Waitzberg DL, Bellinati-Pires R, Salgado MM, et al. Effect of total parenteral nutrition with different lipid emulsions on human monocyte and neutrophil functions. Nutrition 1997; 13: 128-32.

28 Kuse ER, Kotzerke J, Müller S, Nashan B, Lück R, Jaeger $K$. Hepatic reticuloendothelial function during parenteral nutrition including an MCT/LCT or LCT emulsion after liver transplantation - a double-blind study. Transpl Int 2002; 15: 272-7.

29 Borgeat A, Popovic V, Nicole A, Schwander D. Acute pulmonary oedema following administration of ornithine-8-vasopression. Br J Anaesth 1990; 65: 548-51.

30 Soto J, Sacristan JA, Alsar MJ. Pulmonary oedema due to fentanyl? (Letter). Anaesthesia 1992; 47: 913-4. 